Letter

\title{
Evolution of Backscattering Coefficients of Drifting Multi-Year Sea Ice during End of Melting and Onset of Freeze-up in the Western Beaufort Sea
}

\author{
Seung Hee Kim ${ }^{1}{ }^{(}$, Hyun-Cheol Kim ${ }^{1} *{ }^{\circledR}$, Chang-Uk Hyun ${ }^{1}\left(\mathbb{D}\right.$, Sungjae Lee ${ }^{1}{ }^{\circledR}$, Jung-Seok Ha ${ }^{2}$, \\ Joo-Hong Kim ${ }^{1}$, Young-Joo Kwon ${ }^{1}{ }^{\circledR}$, Jeong-Won Park ${ }^{1}$, Hyangsun Han ${ }^{3}{ }^{\circledR}$, Seong-Yeob Jeong ${ }^{2}$ \\ and Duk-jin Kim ${ }^{4}$ \\ 1 Unit of Arctic Sea-Ice Prediction, Korea Polar Research Institute, Incheon 21990, Korea; \\ seunghee@kopri.re.kr (S.H.K.); chyun@kopri.re.kr (C.-U.H.); sungjae@kopri.re.kr (S.L.); \\ joo-hong.kim@kopri.re.kr (J.-H.K.); kwonyj@kopri.re.kr (Y.-J.K.); jeong-won.park@kopri.re.kr (J.-W.P.) \\ 2 Korea Research Institute of Ships \& Ocean Engineering, Daejeon 34103, Korea; jsha@kriso.re.kr (J.-S.H.); \\ jsyeop@kriso.re.kr (S.-Y.J.) \\ 3 Division of Geology \& Geophysics, Kangwon National University, Chuncheon 24341, Korea; \\ hyangsun@kangwon.ac.kr \\ 4 School of Earth and Environmental Sciences, Seoul National University, Seoul 08826, Korea; djkim@snu.ac.kr \\ * Correspondence: kimhc@kopri.re.kr
}

Received: 7 March 2020; Accepted: 24 April 2020; Published: 27 April 2020

\begin{abstract}
Backscattering coefficients of Sentinel-1 synthetic aperture radar (SAR) data of drifting multi-year sea ice in the western Beaufort Sea during the transition period between the end of melting and onset of freeze-up are analyzed, in terms of the incidence angle dependence and temporal variation. The mobile sea ice surface is tracked down in a $1 \mathrm{~km}$ by $1 \mathrm{~km}$ region centered at a GPS tracker, which was installed during a field campaign in August 2019. A total of 24 Sentinel-1 images spanning 17 days are used and the incidence angle dependence in $\mathrm{HH}$ - and HV-polarization are $-0.24 \mathrm{~dB} / \mathrm{deg}$ and $-0.10 \mathrm{~dB} / \mathrm{deg}$, respectively. Hummocks and recently frozen melt ponds seem to cause the mixture behavior of surface and volume scattering. The normalized backscattering coefficients in $\mathrm{HH}$ polarization gradually increased in time at a rate of $0.15 \mathrm{~dB} /$ day, whereas the HV-polarization was relatively flat. The air temperature from the ERA5 hourly reanalysis data has a strong negative relation with the increasing trend of the normalized backscattering coefficients in $\mathrm{HH}$-polarization. The result of this study is expected to complement other previous studies which focused on winter or summer seasons in other regions of the Arctic Ocean.
\end{abstract}

Keywords: sea ice; synthetic aperture radar; multi-year; arctic; Beaufort Sea; backscattering coefficient; incidence angle

\section{Introduction}

The Arctic Sea ice cover plays an important role in mediating the global climate through the ice-albedo feedback mechanism [1]. Over recent decades, the Arctic climate has been shifting rapidly and sea ice extent and thickness have substantially declined with more and more extreme cases [2-5]. In particular, the September extent has shown an exceptional decline trend with higher frequency of the lowest extents and prediction of the ice-free September Arctic Ocean after the year 2100 [6-8]. As sea ice extent and thickness decreases, thick multi-year sea ice (MYI) has been replaced by thinner first-year sea ice (FYI) [5,9].

Active remote sensing that operates in the microwave portion of the electromagnetic spectrum has been used to produce sea ice information. Synthetic aperture radar (SAR) for the most part has been an 
efficient tool in several sea ice applications, owing to its all-weather and 24-hour high-resolution data which can distinguish between sea ice, snow, and open water [10-13]. In particular, longer wavelength SAR sensors with multiple polarizations have been proven to effectively distinguish between FYI and MYI as the backscatter contrast is high [14-17].

Precise radiometric calibration of SAR data is required for the accurate classification of sea ice. The compensation of the incidence angle dependence is a part of the required calibration, which can significantly influence backscatter and lead to misclassification unless properly done [18]. Several studies have analyzed the incidence angle dependence of sea ice surfaces in various regions of the Arctic (e.g., MYI in north of Fram Strait using ENVISAT Advanced Synthetic Aperture Radar (ASAR) with HH polarization in melt season [19], MYI and FYI with various thickness in summer using an in situ scatterometer with VV polarization [20], MYI and FYI in the northern Canadian Arctic Archipelago in winter using RADARSAT-2 with $\mathrm{HH}$ polarization [21]). In general, the backscatter linearly decreases as a function of incidence angle for both MYI and FYI, and the dependence is larger for FYI than for MYI.

However, the spatial and temporal variation of sea ice characteristics requires additional analysis on the incidence angle dependence in different regions and time of year. In particular, the backscattering behavior, as well as the incidence angle dependence in the marginal ice zone (MIZ), have hardly been observed. Similarly, any temporal observation during the transition period from summer melting to winter freezing in the MIZ has not been carried out. The MIZ is a dynamic region between consolidated ice and open water, where intense atmosphere-ice-ocean interactions take place [22]. The importance of the MIZ has increased in recent years toward the understanding of ice-ocean-atmosphere interactions [22,23].

Nevertheless, the following reasons might have caused a lack of observation and analysis in the MIZ. First of all, the precise classification between MYI and FYI within this area remains a challenge, owing to the high ambiguity between a mixture of different ice types [10]. In summer, MYI and FYI results in similar radar returns due to melt ponds and homogeneous surface wetness [24]. Besides, MYI that survived the summer contains hummocks and melt ponds which can contribute to volume and surface scattering of the incoming microwave, respectively, making the interpretation of SAR images difficult. During the onset of freeze-up, melt ponds start freezing as the air temperature decreases, adding complexity.

Secondly, sea ice floes in the marginal ice zone are highly mobile, requiring a robust selection method of sample windows. Most studies with active radar images manually selected sample windows of ice surfaces based on the tone and texture [19-21]. This could be problematic, because there is no guarantee that selected ice surfaces were the same ice types; even in a single satellite image, and different ice types can have similar backscattering characteristics [25]. Continuous tracking of the same ice surface in different images at different times could be another possible problem of the manual selection, except for those sample windows which comprise landfast ice, such as the northern interior of the Canadian Arctic Archipelago where ice remains locked in place until summer break-up [21]. Thus, monitoring changes of mobile ice floes in highly variable sectors of the Arctic requires a robust selection method of sample windows.

This study analyzes the incidence angle dependence of drifting MYI in the marginal ice zone of the western Beaufort Sea between the end of melt and the onset of freeze-up using time-series Sentinel-1 C-band SAR data. The western Beaufort Sea has been experiencing severe sea ice extent and thickness decline in recent years $[9,26]$, requiring repeated observation in the MIZ for a better understanding of diminishing sea ice. A GPS tracker is used to track down the same ice floe in motion, increasing robustness of sample window selection. Finally, the temporal analysis of the backscattering characteristics of MYI in the MIZ is carried out for the first time.

\section{Materials and Methods}

\subsection{Study Area}

This study focuses on a large sea ice floe in the marginal ice zone of the western Beaufort Sea, north of Alaska, where a field campaign was carried on from August 12 to 15 in 2019 by ice breaker research 
vessel (IBRV) Araon (Figure 1a). This campaign was the first of two field campaigns that were carried out during the Arctic survey in 2019. Based on an airborne survey by a helicopter and field surveys, the surface of ice floe contained hummocks and wide melt ponds, of which surfaces were frozen at that time (Figure 1b). The surface water drainage could occur well before the onset of freeze-up on FYI, as early as in June [27,28]; however, the perforation was not observed within $100 \mathrm{~m}$ radius from the IBRV Araon based on the field campaign. The average air temperature during the field campaign, measured from IBRV Araon, was $-0.89 \pm 0.70{ }^{\circ} \mathrm{C}$. The sea ice floe was determined as a multi-year ice, based on the salinity, temperature, and density measurements of 4 ice cores with a diameter of $9 \mathrm{~cm}$, which were extracted at 3 different sites. Each ice core was sliced into $10-\mathrm{cm}$ pieces, where small holes were drilled amid each piece for temperature measurement immediately after the ice was extracted. Ice temperatures were measured in those small holes, using a digital thermometer with an accuracy of $\pm 0.1^{\circ} \mathrm{C}$. The salinity was measured using a YSI Pro30 salinometer with an accuracy of $0.1 \mathrm{ppt}$. The upper part of the ice floe consisted of a fresh low-density layer $\left(600 \mathrm{~kg} \cdot \mathrm{m}^{-3}\right.$ for the lowest) lying over higher density layers, and salinity increases to 3 ppt with the thickest ice core of $3.5 \mathrm{~m}$ (Figure 2a,b). Temperature decreases almost linearly to the freezing point $\left(-1.7^{\circ} \mathrm{C}\right)$ from the surface to the bottom of the ice (Figure $2 \mathrm{c}$ ).
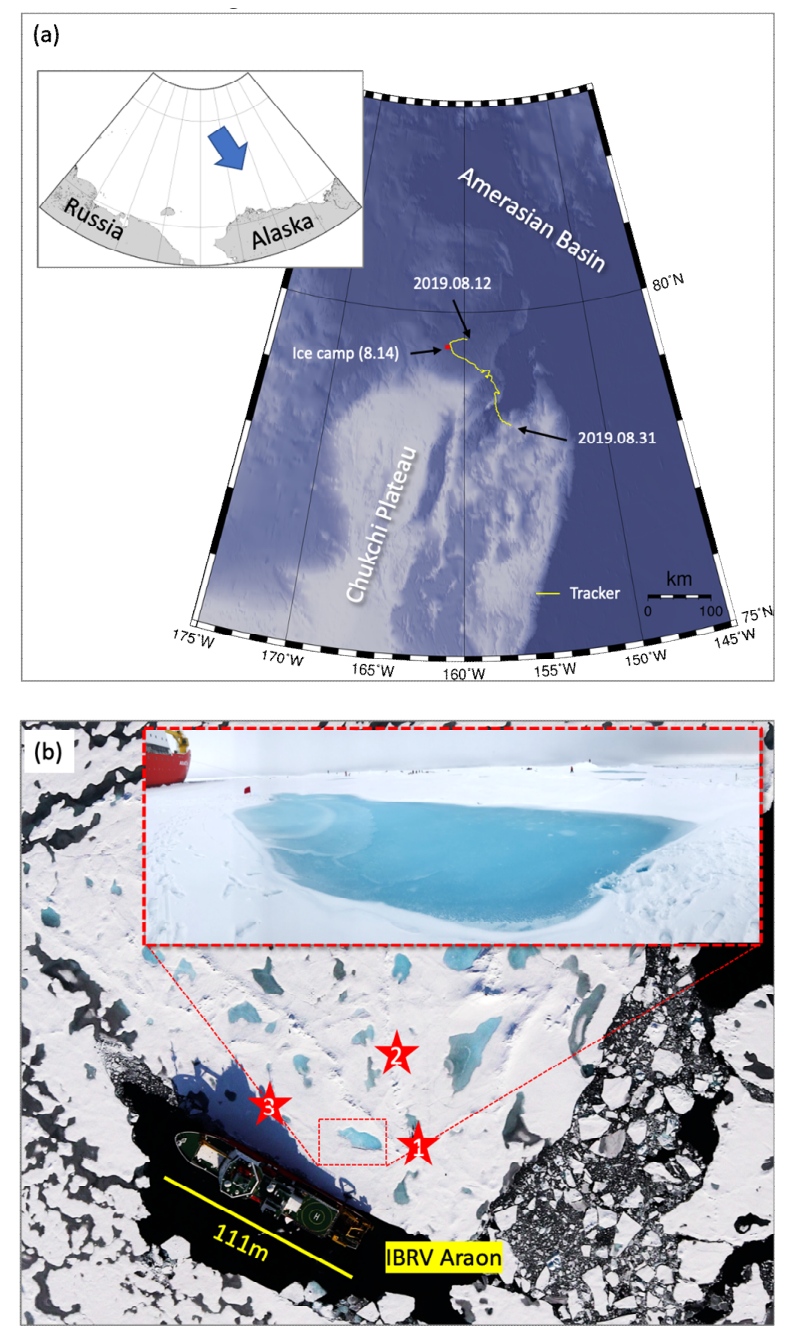

Figure 1. (a) Sea ice field campaign (ice camp) was carried on a large ice floe drifting in the marginal ice zone in the western Beaufort Sea in August 2019. Location of the ice camp on 12 August, 2019, is denoted as a red dot, while the drift of the ice floe is in yellow. (b) Surface of the ice floe, captured on a helicopter, contained hummocks and melt-ponds, which were frozen at the time of the campaign. (inlet). Red stars indicate the locations of ice coring sites. The length of ice breaker research vessel (IBRV) Araon is inserted for scale. 

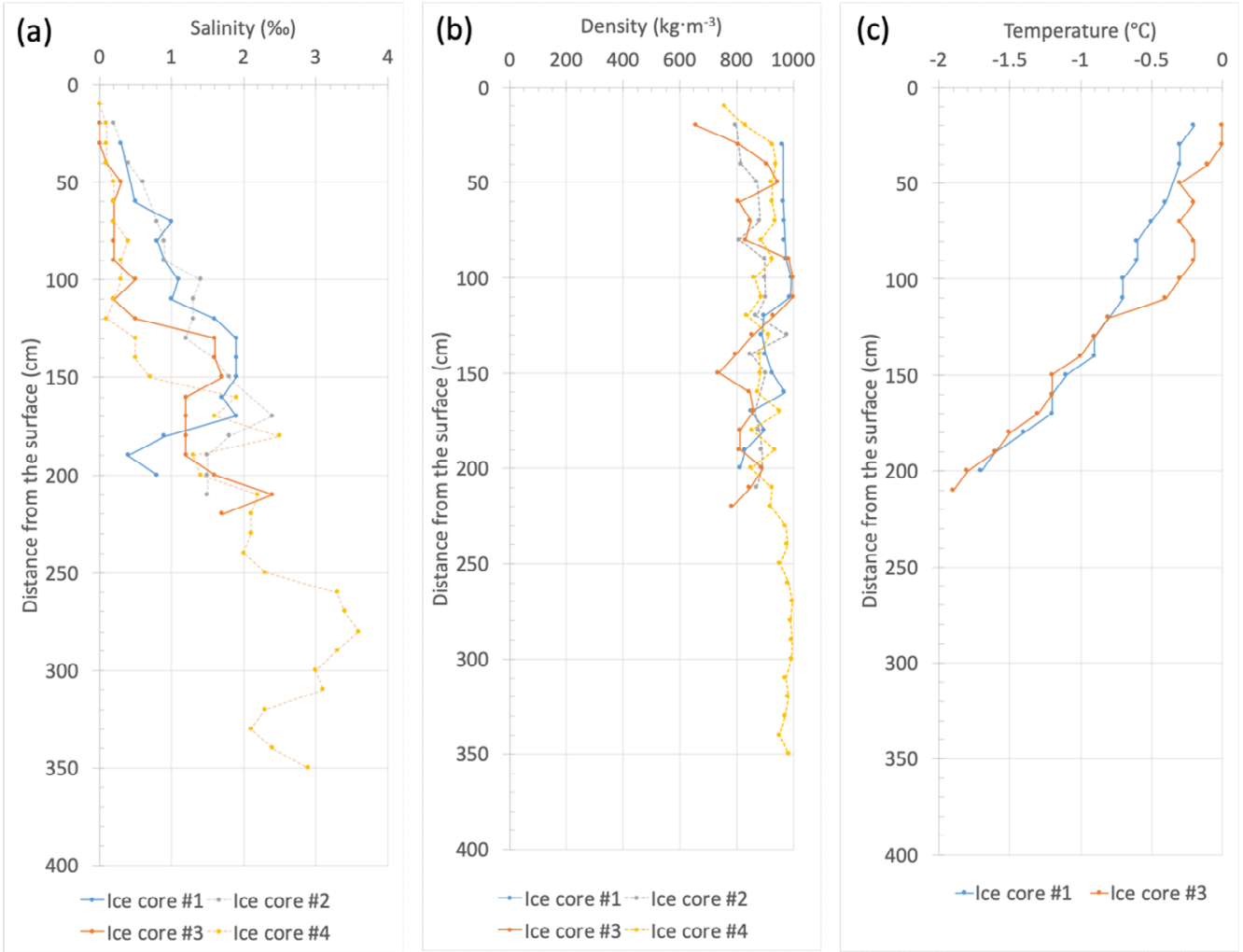

Figure 2. (a) Salinity, (b) density, and (c) temperature profiles of the extracted ice cores during the field campaign during August 12-15 in 2019 represent the characteristics of multi-year sea ice with low salinity and density on the top layer.

\subsection{Methods}

\subsubsection{Installation of a GPS Tracker on a Sea Ice Floe}

A sea ice drifter buoy, developed by the Yotta Ocean in South Korea, with an integrated GNSS positioning system and Argos satellite-based data transmission system, was installed on the surface of the sea ice floe during the field campaign on 12 August, 2019. The coordinates of the tracker were recorded every hour and remotely transmitted to the web-based server (www.spotmyglobalstar.com) via satellite communication. The operating temperature range of the buoy was between -30 and $60{ }^{\circ} \mathrm{C}$ and the expected operation period was 12 months. The tracker was firmly fixed in the ice using wood frames and weights, to prevent loss from strong wind or marine mammals. The time and coordinates of the tracker on the ice floe were used to select Sentinel 1A/B satellite images that simultaneously capture the sea ice floe within its swath.

\subsubsection{Processing of Sentinel-1 C-Band SAR Data}

Sentinel-1 extra wide (EW) Ground Range Detected Medium Resolution (GRDM) SAR images in $\mathrm{HH}$ - and HV-polarization covers over a $400 \mathrm{~km}$ swath at $40 \mathrm{~m}$ spatial resolution [29]. The incidence angle ranges from $18.9^{\circ}$ to $47.0^{\circ}$, combining 5 sub-swaths. Sentinel- 1 images are radiometrically and geometrically calibrated using European Space Agency's Sentinel-1 Toolbox software, so that the pixel values can be related to the radar backscatter of the sea ice surface. In the radiometric calibration, the backscattering coefficients of Sentinel-1 data are retrieved after applying the precise orbit information and removing the thermal noise. The backscattering coefficients are filtered to reduce speckle noise using a Lee filter with a window size of 11 by 11 pixels. The radiometrically calibrated images are then projected to the WGS84 NSIDC Sea Ice Polar Stereographic North (EPSG:3413), with a pixel size of $100 \mathrm{~m}$. 
2.2.3. Calculation of the Incidence Angle Dependence and Temporal Analysis of the Normalized Backscattering Coefficients

For every radiometrically and geometrically calibrated Sentinel-1 EW image in $\mathrm{HH}$ and HV-polarization, the backscattering coefficients and incidence angle at corresponding coordinates of the GPS tracker are extracted. The range of incidence angle is expected to be well distributed, benefitting from swath overlap at high latitudes [29]. Sentinel-1 data with the temporal difference from the GPS point less than 1-hour are selected, in order to minimize spatial error from continuously drifting sea ice. For example, 6-hour difference from the tracker creates over $10 \mathrm{~km}$ offset from the actual ice floe. Besides, interpolation of the recorded GPS coordinates is not carried out, owing to non-linear drift (speed and rotation) of the ice floe. Then, mean (shown as $\sigma^{0}{ }_{p p}$ in Tables 1 and 2) and standard deviation (shown as $S\left(\sigma_{\mathrm{pp}}^{0}\right)$ in Tables 1 and 2 ) of the backscattering coefficients around extracted coordinates with a radius of $500 \mathrm{~m}$ are calculated, where pp denotes polarization, $\mathrm{HH}$ or HV. The sample window is decided for comparison with previous studies (i.e., Mahmud et al. [21]; Mäkynen and Karvonen [30]), and the spatial constraint is necessary to isolate from FYI and large open water, which could possibly be present around the ice floe of interest.

The incidence angle dependence is modelled as a first-order polynomial, with respect to the backscattering coefficients of $\mathrm{HH}$ - and $\mathrm{HV}$-polarization [18]. The $\mathrm{R}^{2}$ and root mean square error between the observed and modelled backscattering coefficients are calculated for the goodness of fit. The $p$-value for the coefficient is determined to test significance level. The backscattering coefficients are normalized (shown as $\mathrm{N}\left(\sigma_{\mathrm{pp}}^{0}\right)$ in Tables 1 and 2) for further analysis, using the derived regression model with respect to a particular reference angle, as in Mahmud et al. [21] In this study, the reference angle for the normalization of the backscattering coefficients is $33^{\circ}$, the middle-angle of Sentinel- 1 EW image [18]. Then, a fist-order polynomial regression model is used to determine a temporal trend of the normalized backscattering coefficients over the surface of multi-year sea ice during the observation period. The $\mathrm{R}^{2}$ and root mean square error between the observed and predicted backscattering coefficients are calculated. The $p$-value for the coefficient is determined to test the significance level.

\subsubsection{Atmospheric Effects on the Backscattering Coefficients}

2-m temperature, instantaneous 10-m wind gust, and mean sea level pressure from the ERA5 hourly reanalysis dataset on single levels are analyzed, in an attempt to comprehend the weather-induced variation of backscattering coefficients. ERA5 is the fifth-generation atmospheric reanalysis of the global climate by the European Centre for Medium-range Weather Forecasts (ECMWF), which has a horizontal resolution of $0.25^{\circ}$ by $0.25^{\circ}$ and temporal resolution of 1 hour [31]. The hourly profile of each atmospheric variable at the coordinates of the installed GPS tracker is extracted by the linear interpolation between the grids using the recorded GPS data. Then, the parameter values of the atmospheric variables at corresponding times of Sentinel-1 data are estimated by linear interpolation between the profile points. Finally, 13-day records of air temperature and pressure from a buoy, installed in the inner part of the ice floe, are used to validate the reanalysis datasets. The recording period was much shorter than the GPS tracker, because the buoy was recovered on the way back owing to the frequent visit of a polar bear at the deployed site. The Spearman correlation coefficient with $p$-value is used to analyze the degree of association between the Sentinel-1 data and the atmospheric variables. The atmospheric variables from the reanalysis dataset are chosen based on the availability of in situ measurements for validation and the weather report from IBRV Araon during the field survey.

\section{Results}

The GPS tracker successfully transmitted its coordinates every hour from 12 August, 2019, and kept on recording its location until November of the same year. We visually checked every available Sentinel-1 EW which showed a continuous decrease in the ice concentration around the ice floe. A total of 24 images spanning 17 days, from 15 to 31 August, 2019, were selected for analysis. 
Figure 3 shows radiometrically calibrated Sentinel-1A/B images in $\mathrm{HH}$-polarization which were used for the analysis of the incidence angle dependence, and later of temporal variation. A red square inside each image indicates a sample window of $1 \mathrm{~km}$ by $1 \mathrm{~km}$ which backscatter statistics were calculated. It is clear that the incidence angle induces substantial difference between the images that were acquired on the same date. It became unclear whether the ice floe completely melted, or the GPS tracker was detached from an ice floe after 1 September 2019 (Figure 4b). Besides, the images between 12 and 15 August 2019 were not used, because they were contaminated by a strong backscattering signal of IBRV Araon in the vicinity of the tracker.

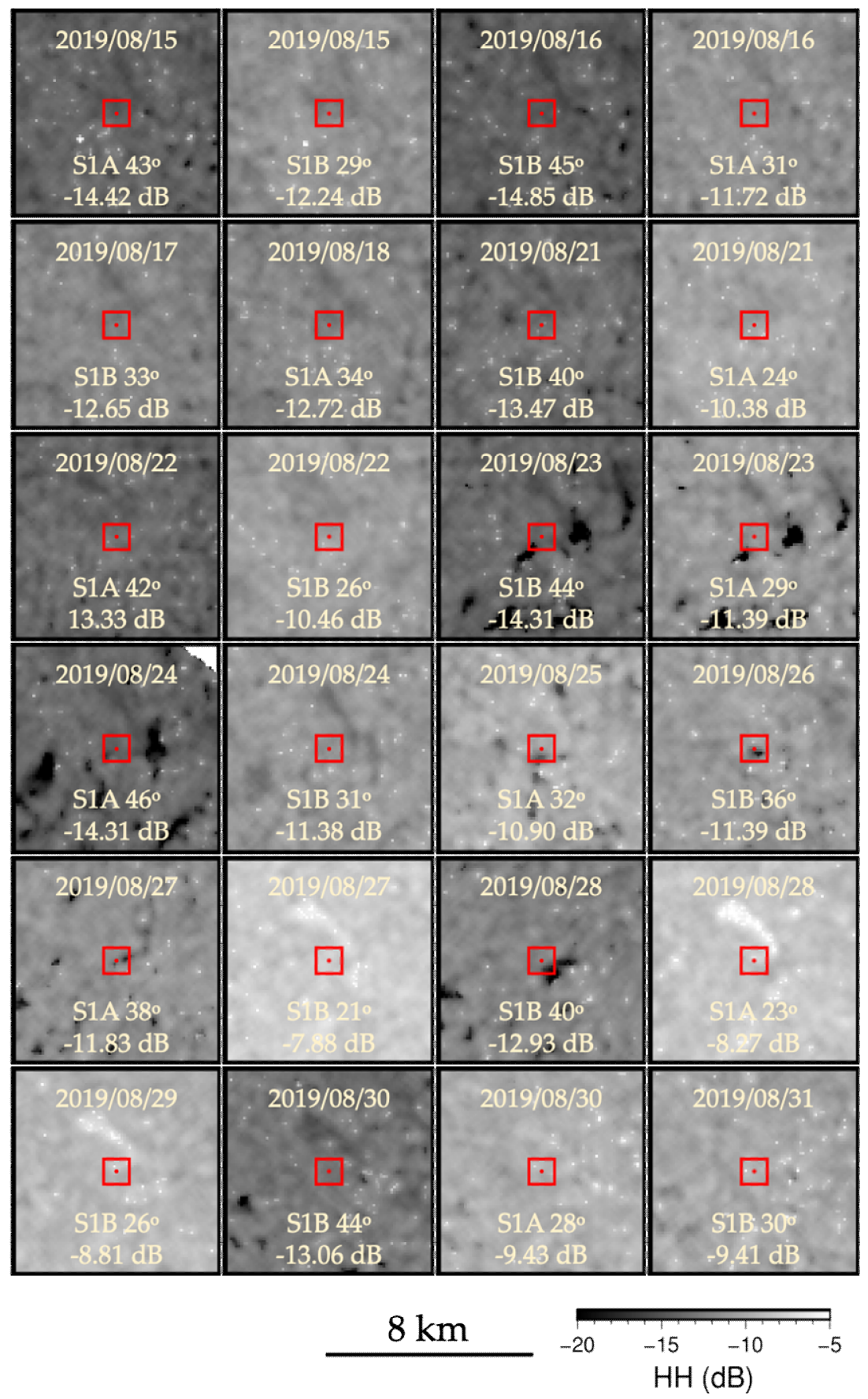

Figure 3. Time-series of radiometrically calibrated Sentinel-1A/B images in HH-polarization, along with the acquisition date and incidence angle. A red square indicates a sample window of $1 \times 1 \mathrm{~km}$ which backscatter statistics were calculated. 
(a)

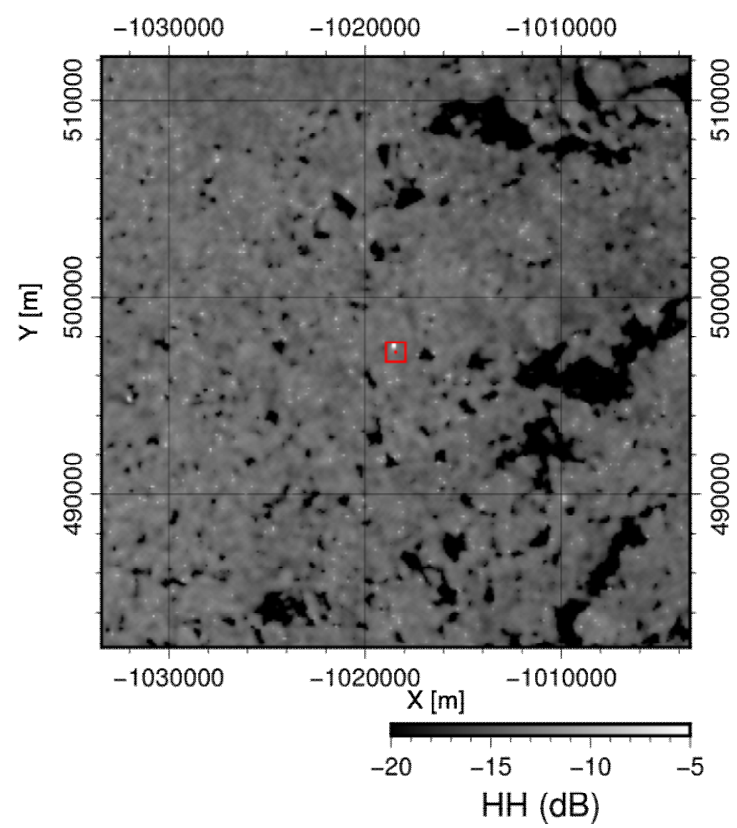

(b)

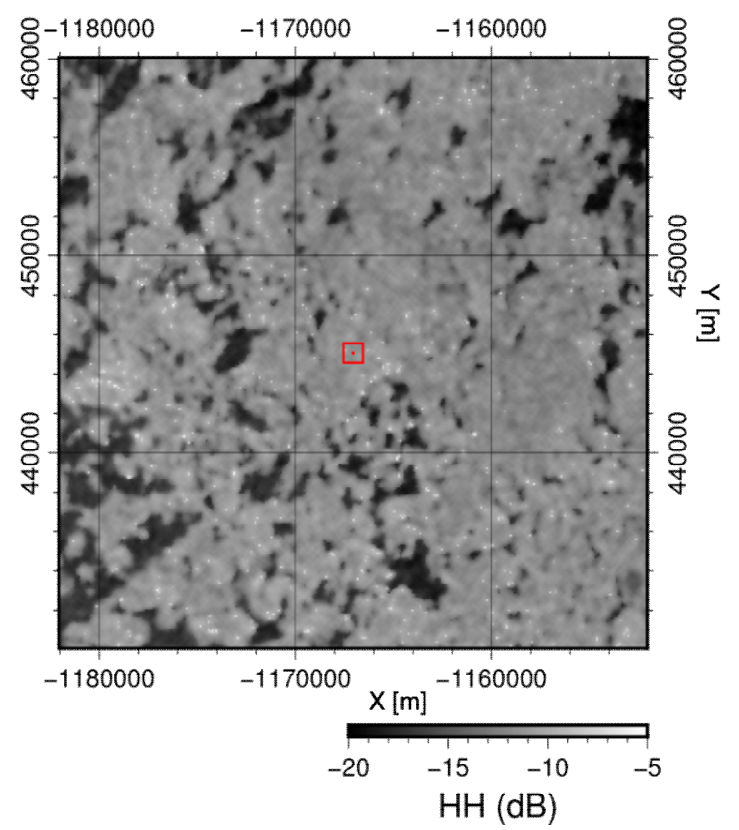

Figure 4. (a) Sentinel-1B image in HH-polarization, acquired at 17:53 UTC (08:53 local time in Alaska) on 14 August 2019. The bright signal is IBRV Araon. (b) Sentinel-1B image at 17:45 UTC (08:45 local time in Alaska) on 2 September 2019, the surround of the ice floe became indistinguishable. A red square indicates the sample window within which backscatter statistics were calculated.

Figure 4a shows a subset of radiometrically calibrated Sentienl-1B image on 14 August, 2019 in a descending orbit, centered at the coordinates of the GPS tracker on the ice floe, shown as a red square. The time difference between the tracker and Sentinel-1 image is 6 minutes and a bright signal near the GPS coordinates is IBRV Araon, which stayed at the site until 15 August, 2019, for a field survey on the ice floe. For 17 days, the ice floe drifted about $100 \mathrm{~km}$ to the southeast, moving around the edge of the Chukchi Plateau, where the Beaufort Gyre usually moves counterclockwise (Figure 1a). The total distance of drift was $245 \mathrm{~km}$, with the highest instantaneous drifting speed being $2 \mathrm{~km} / \mathrm{h}$ on 25 August in 2019.

Notably, $\sigma^{0} \mathrm{HH}$ and ${ }^{0} \mathrm{HV}$ of Sentinel-1 over the multi-year sea ice surface showed a strong linear relationship with the incidence angle. $\sigma^{0}$ are plotted against the well-distributed incidence angles ranging from $21^{\circ}$ and $46^{\circ}$, with the standard deviation as error bars (Figure 5a). The minimum, maximum, and mean of $\sigma^{0} \mathrm{HH}$ are $-14.85 \mathrm{~dB},-7.89 \mathrm{~dB}$, and $-11.39 \mathrm{~dB}$, with the standard deviation of $2.00 \mathrm{~dB}$, respectively; and $\sigma^{0} \mathrm{HV}$ are $-24.54 \mathrm{~dB},-21.31 \mathrm{~dB}$, and $-23.07 \mathrm{~dB}$, with the standard deviation of $0.98 \mathrm{~dB}$, respectively (Table 1). The spatial standard deviations of $\mathrm{HH}$ - and HV-polarization ranged from 0.28 and $0.39 \mathrm{~dB}$ to 4.96 and $4.79 \mathrm{~dB}$.

Then, $\sigma^{0} \mathrm{HH}$ and $\sigma^{0} \mathrm{HV}$ decreased as the incidence angle increased with a slope of $-0.24 \pm 0.02 \mathrm{~dB} / \mathrm{deg}$ and $-0.10 \pm 0.02 \mathrm{~dB} / \mathrm{deg}$, respectively. The root mean square error from the linear least squares fitting line was $0.73 \mathrm{~dB}$ and $0.66 \mathrm{~dB}$, with $\mathrm{R}^{2}$ of 0.82 and 0.59 for $\mathrm{HH}$ and $\mathrm{HV}$, respectively, with the confidence level of 99 percent $(p$-value $<0.01)$ (Table 2).

Using the derived polynomial regression model as described in Section 2.2.3, radiometrically calibrated backscattering coefficients were normalized with respect to the reference angle of $33^{\circ}$, the middle-incidence angle of Sentinel-1 EW mode. After normalization, the difference between minimum and maximum and standard deviation of the mean backscattering coefficients in HH-polarization, $\mathrm{N}\left(\sigma^{0} \mathrm{HH}\right)$, decreased, as shown in Table 1. The mean backscattering coefficients in HV-polarization, $\mathrm{N}\left(\sigma^{0} \mathrm{HV}\right)$, exhibited subtle changes. The difference between the minimum and maximum normalized backscattering coefficients of the ice surface was around $3 \mathrm{~dB}$ both in $\mathrm{HH}$ - and HV-polarization. 
Table 1. Minimum, maximum, mean, and standard deviation of the un-normalized $\left(\sigma^{0} \mathrm{HH}\right)$, normalized $\left(\mathrm{N}\left(\sigma^{0}{ }_{\mathrm{HH}}\right)\right)$ backscattering coefficients and spatial standard deviations $\left(\mathrm{S}\left(\sigma^{0}{ }_{\mathrm{HH}}\right)\right)$ in a $1 \mathrm{~km}$ by $1 \mathrm{~km}$ region of interest in $\mathrm{HH}$ - and $\mathrm{HV}$-polarization.

\begin{tabular}{cccc}
\hline & Min [dB] & Max [dB] & Mean [dB] \\
\hline$\sigma^{0}{ }_{\mathrm{HH}}$ & -14.85 & -7.89 & $-11.73 \pm 2.00$ \\
$\mathrm{~N}\left(\sigma^{0} \mathrm{HH}\right)$ & -13.10 & -10.01 & $-11.39 \pm 0.84$ \\
$\sigma^{0} \mathrm{HV}$ & -24.54 & -21.31 & $-23.07 \pm 0.98$ \\
$\mathrm{~N}\left(\sigma^{0} \mathrm{HV}\right)$ & -24.44 & -21.20 & $-22.93 \pm 0.67$ \\
\hline $\mathrm{S}\left(\sigma^{0} \mathrm{HH}\right)$ & 0.28 & 4.96 & $1.03 \pm 0.92$ \\
$\mathrm{~S}\left(\sigma^{0} \mathrm{HV}\right)$ & 0.39 & 4.79 & $1.52 \pm 0.78$ \\
\hline
\end{tabular}

Table 2. The statistical relations, $\mathrm{R}^{2}$, the Spearman coefficient $\rho$, and $p$-value, for the backscattering coefficients $\left(\sigma^{0}\right)$, the normalized backscattering coefficients $\left(\mathrm{N}\left(\sigma^{0}\right)\right)$, and the spatial standard deviations $\left(\mathrm{S}\left(\sigma^{0}\right)\right)$, in both polarizations with the atmospheric variables.

\begin{tabular}{|c|c|c|c|c|c|c|c|}
\hline & & $\sigma^{0} \mathrm{HH}$ & $\sigma^{0} \mathrm{HV}$ & $\mathbf{N}\left(\sigma^{0}{ }_{\mathrm{HH}}\right)$ & $\mathrm{N}\left(\sigma^{0}{ }_{\mathrm{HV}}\right)$ & $\mathrm{S}\left(\sigma_{\mathrm{HH}}^{0}\right)$ & $\mathrm{S}\left(\sigma^{0}{ }_{\mathrm{HV}}\right)$ \\
\hline \multirow{3}{*}{$\begin{array}{l}\text { Incidence } \\
\text { Angle }\end{array}$} & Slope $[\mathrm{dB} / \mathrm{deg}]$ & -0.24 & -0.10 & & & & \\
\hline & $R^{2}$ & 0.82 & 0.59 & & & & \\
\hline & $p$-value & $<0.01$ & $<0.01$ & & & & \\
\hline \multirow{3}{*}{ Time } & Slope [dB/day] & 0.22 & 0.10 & 0.15 & 0.06 & & \\
\hline & $\mathrm{R}^{2}$ & 0.28 & 0.25 & 0.76 & 0.24 & & \\
\hline & $p$-value & 0.008 & 0.012 & $<0.01$ & 0.017 & & \\
\hline \multirow{2}{*}{$\begin{array}{c}\text { Air } \\
\text { temperature }\end{array}$} & $\rho$ & & & -0.69 & -0.48 & -0.14 & -0.46 \\
\hline & $p$-value & & & $<0.01$ & 0.018 & 0.502 & 0.026 \\
\hline \multirow{2}{*}{ Wind gust } & $\rho$ & & & -0.07 & 0.37 & -0.16 & -0.12 \\
\hline & $p$-value & & & 0.728 & 0.079 & 0.456 & 0.567 \\
\hline \multirow{2}{*}{ Pressure } & $\rho$ & & & -0.20 & -0.42 & -0.34 & -0.49 \\
\hline & $p$-value & & & 0.339 & 0.044 & 0.103 & 0.015 \\
\hline
\end{tabular}

$\mathrm{N}\left(\sigma^{0} \mathrm{HH}\right)$ showed a gradual increase as time progressed with a trend of $0.15 \pm 0.02 \mathrm{~dB} /$ day, with the confidence level of 99 percent (Table 2). $R^{2}$ was 0.76 and the root mean square error was $0.44 \mathrm{~dB}$, when fitted using linear least squares regression (Figure $5 b) . \mathrm{N}\left(\sigma^{0} \mathrm{HV}\right.$ ) also showed an increasing trend as time progressed, although the slope was relatively small, $0.06 \pm 0.02 \mathrm{~dB} /$ day with $\mathrm{R}^{2}$ of 0.24 and root mean square error of $0.53 \mathrm{~dB}$ with a confidence level of 95 percent (Table 2), when fitted using linear least squares regression.

Figure 6 shows the time series of 2-m air temperature, maximum instantaneous wind gust at $10 \mathrm{~m}$, and mean sea level pressure from the hourly ERA5 reanalysis dataset, with the in situ air temperature and pressure measured at a height of $2 \mathrm{~m}$ on a buoy (dashed red lines). The reanalysis datasets correlate well with the in situ measurements. 
(a)

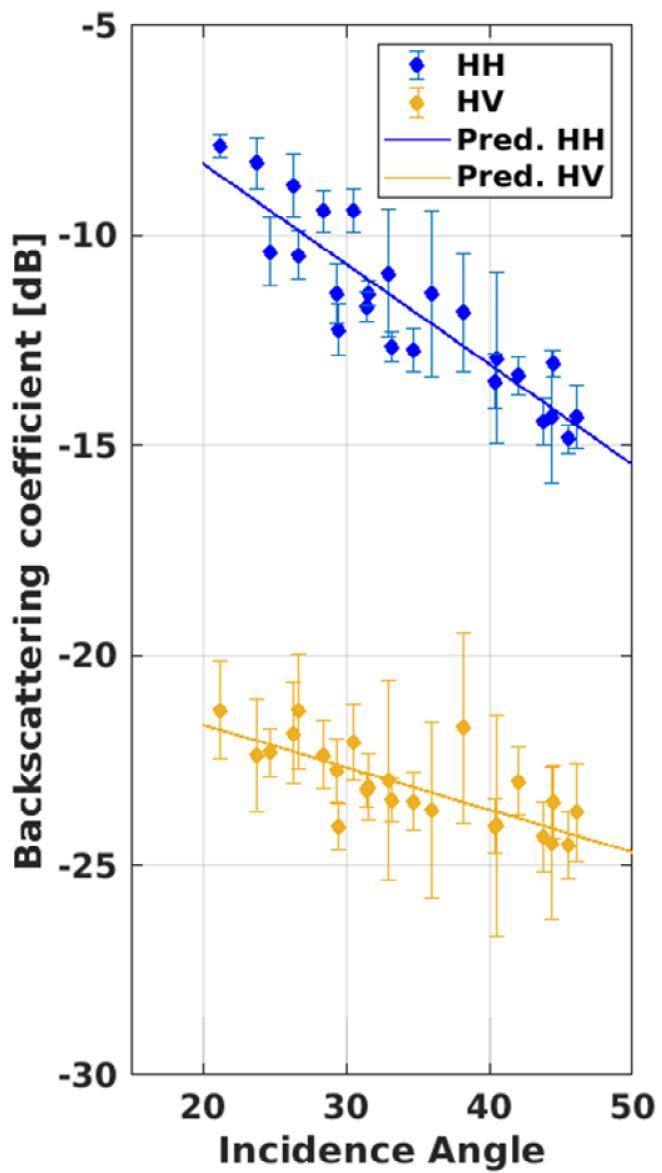

(b)

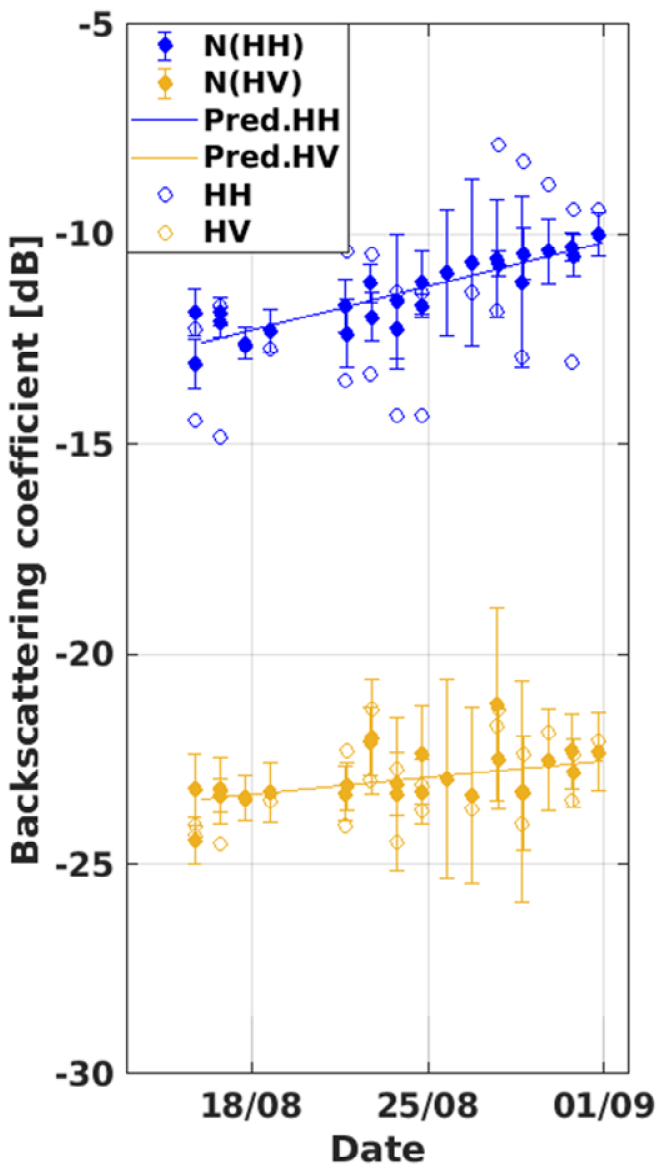

Figure 5. (a) Scatterplot of the backscattering coefficients of Sentinel- $1 \mathrm{EW}$ data in $\mathrm{HH}-\left(\sigma^{0} \mathrm{HH}\right)$ and HV-polarization $\left(\sigma^{0} \mathrm{HV}\right)$ over the multi-year sea ice (MYI) surface with respect to the incidence angle. (b) Temporal variation of the incidence angle corrected $\left(\mathrm{N}\left(\sigma^{0}\right)\right)$, predicted, and un-normalized $\left(\sigma^{0}\right)$ backscattering coefficients.

The research period for which Sentinel-1 SAR data were gathered is denoted by a horizontal black bar at the bottom of each panel. Black vertical lines over the horizontal bar indicate the acquisition times of Sentinel-1A/B data. Some lines are indistinguishable due to close proximity between Sentinel-1 $\mathrm{A}$ and $\mathrm{B}$ acquisitions. The air temperature is smoothed by a Gaussian filter with a width of 24-hour to represent a general pattern. The air temperature fell below freezing on 13 Aug 2019 for the first and the diurnal variation stayed below freezing on 20 August 2019 and thereafter. It should be noted that the wind gust was considerably high after 20 August 2019, with strong low pressure. The highest wind gust was $21.72 \mathrm{~m} / \mathrm{s}$ on 25 August 2019, when the temperature and pressure dropped largely (Figure 6). The statistical relations, the Spearman coefficient $\rho$ and $p$-value, between the normalized backscattering coefficients in both polarizations, as well as the spatial standard deviations and the atmospheric variables, are listed in Table 2. The normalized backscattering coefficients in both polarizations are strongly correlated with the air temperature. Especially, $\mathrm{N}\left(\sigma^{0} \mathrm{HH}\right)$ shows stronger negative trend with higher confidence level than $\mathrm{N}\left(\sigma^{0} \mathrm{HV}\right)$. The correlation coefficient between $\mathrm{S}\left(\sigma^{0} \mathrm{HV}\right)$ and the pressure at mean sea level show moderate, but negative, relation at the confidence level of 95 percent $(p$-value $=$ 0.015). The rest show low correlation. 

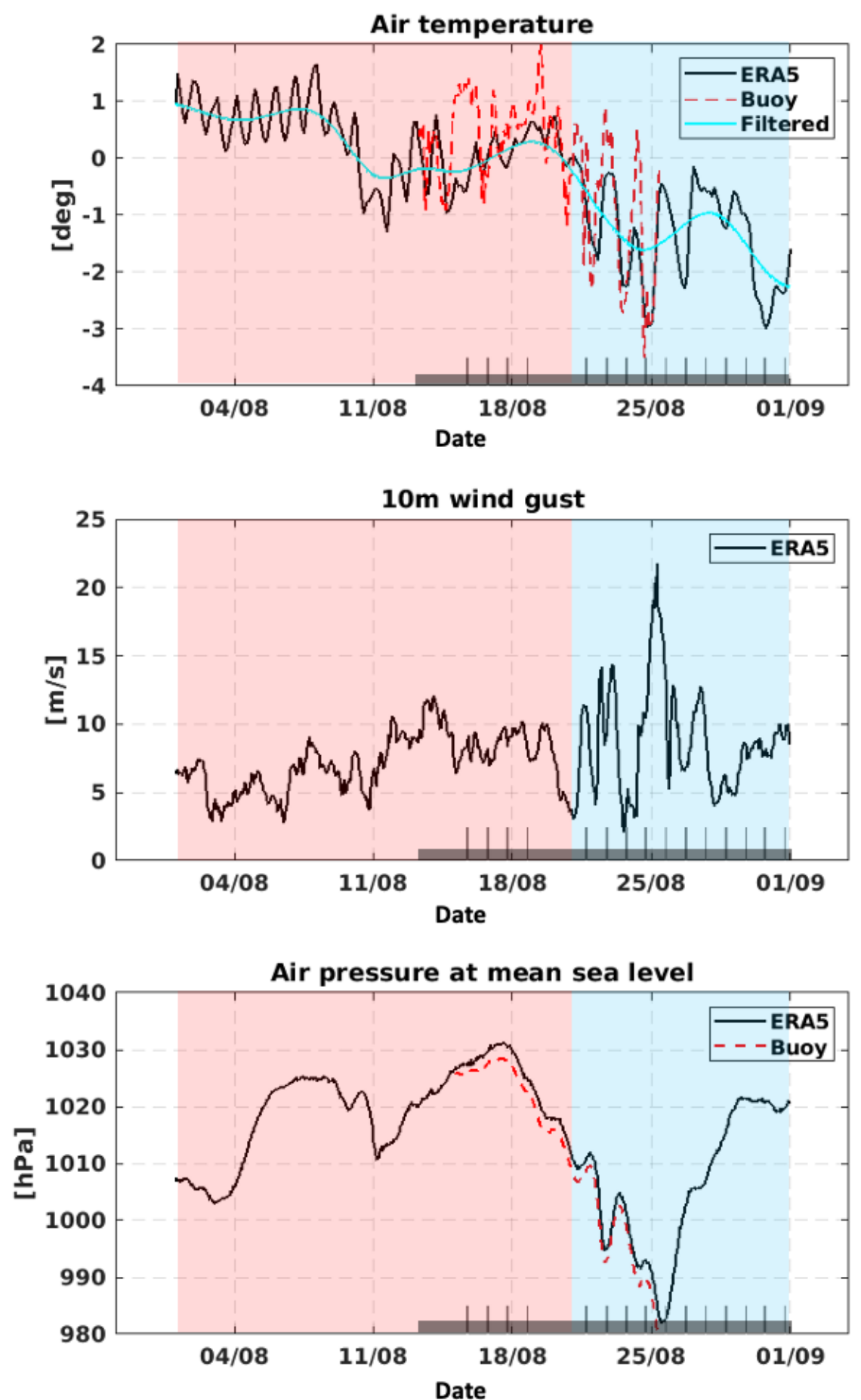

Figure 6. Air temperature, wind gust, and air pressure at mean sea level around the research period are extracted from ERA5 reanalysis data for comparison with the backscattering coefficients. The dark bar at the bottom refers to the research period of which Sentinel-1 data are used and black vertical lines indicate the acquisition times of Sentinel-1 data. In situ measurement by the thermometer and barometer on a buoy are denoted by a dashed red line. The air temperature is smoothed by a Gaussian filter with a width of $24-\mathrm{h}$, denoted by a cyan solid line. The estimated end of melt and onset of freeze-up based on the air temperature was around August 20, 2019, which are expressed by red and blue backgrounds, respectively. 


\section{Discussion}

High $\sigma^{0}$ of the multi-year sea ice in the western Beaufort Sea in late August, both before and after normalization, represent the characteristics of multi-year sea ice well, mainly because of the rough and tilted surfaces of the hummocks [32-34]. The incidence angle dependence of the co-polarized backscattering coefficients $\left(\sigma^{0} \mathrm{HH}\right)$ suggests that the coefficients during the study period are a combination of the surface and volume scattering. In general, the incidence angle dependence is weak $(-0.16 \mathrm{~dB} / \mathrm{deg})$ when the volume scattering is dominant (i.e., multi-year sea ice in winter) [21] and becomes stronger as the surface scattering becomes more dominant in summer, attributed to the melting of the top layer $[18,19,21,30,35]$. In this study, the incidence angle dependence of the multi-year ice of interest still leans to that in summer, although the air temperature fell below freezing. The drop of the air temperature must have increased the volume scattering from bubbles in the upper part of the ice increases [24]. However, the contribution of volume scattering was not significant enough to dramatically weaken the incidence angle dependence.

The cross-polarized backscattering coefficients $\left(\sigma^{0} \mathrm{HV}\right)$ showed weaker incidence angle dependence than the co-polarized, also lower than that of Mäkynen and Karvonen [30] and Geldsetzer et al. [36]. However, the high magnitude of $\sigma^{0} \mathrm{HH}$, staying above the system noise equivalent for Sentinel-1 EW mode data throughout the research period, supports the relatively high confidence level of the regression model (Table 2) [30]. Previous results with $\sigma^{0} \mathrm{HV}$ are scarce; thus, making a conclusion at this time is difficult. Besides, the analysis of the incidence angle dependence for $\sigma^{0} \mathrm{HV}$ on neither FYI nor MYI has been done, whereas it is known that the incidence angle dependence for $\sigma^{0} \mathrm{HH}$ is low when the volume scattering is dominant [21].

The increasing trend of $\sigma^{0} \mathrm{HH}$ is likely linked to the atmospherically forced freezing events. Freezing of the snow and ice top layer would increase contributions of volume scattering from the coarse-grained snow-ice medium between the snow basal layer and ice top [19,37]. The air temperature fell below freezing at the acquisition of Sentinel-1 data (08 09 local time) and the statistical results show that the air temperature has strong negative relation with the increasing trend of $\mathrm{N}\left(\sigma^{0} \mathrm{HH}\right)(\mathrm{r}=-0.72$, $p$-value $=<0.01$ ). Previous research by Jeffries et al. [35] and Winebrenner et al. [24] showed a similar increasing trend in late August. They also measured the Arctic sea ice SAR signature during the melt-season in the western Beaufort Sea using ERS-1 SAR data (VV-pol), that also operated in a similar C-band $(5.6 \mathrm{GHz})$. The central frequency of Sentinel-1 is $5.405 \mathrm{GHz}$.

Although the air temperature mostly stayed below freezing during the study period, it is worth checking whether the surface of melt pond was actually in a frozen state. The correlation between $\sigma^{0}$ and high wind gust during the study period was expected to be significantly high, because a strong surface wind can also substantially increase the C-Band backscattering [28,38]. However, the the surfaces of melt ponds were frozen at least during the field campaign, validated by visual observation, and the correlation was very low. In addition, there is about a $3 \mathrm{~dB}$ difference between 17 and 30 August 2019 when the wind gusts were similar. Therefore, it is unlikely that the surface of melt pond was covered with liquid water during the study period.

The spatial standard deviations of the co-polarized backscattering coefficients within the region of interest around the tracker infer homogeneity of the surface, expecting to be an indirect measurement of physical change of the surface. The correlation is expected to be high for the wind gust, because of the exceptionally high wind gust during the research period (Figure 6); however, the correlation is weak, with the $p$-value showing some feasibility. Thus, wind gust has a subtle effect on the surface changes that affect the backscattering of the radar signal.

On the other hand, the high confidence level with a negative relation between the pressure and $\mathrm{S}\left(\sigma^{0} \mathrm{HV}\right)$ is an intriguing result. Initially, the pressure was tested in an attempt to find any relationship between the SAR backscatter and the Arctic storm. Arctic storms have recently been of interest for sea ice owing to potential impact on the coupled Arctic sea-ice system [39,40]. In this context, the combined effect of high wind speed and possible precipitation at low pressure was expected to perturb 
the backscatter. However, an explanation for the high correlation between $\mathrm{S}\left(\sigma^{0} \mathrm{HV}\right)$ and the pressure is still at large at the moment.

Finally, it should be noted that this ice floe, which was thicker than $3 \mathrm{~m}$, likely disintegrated in about 2 weeks, despite strong evidence of the onset of freeze-up of the ice surface during the study period. The ocean heat in the Beaufort Sea can induce continuous bottom melting after surface melting has ended [41,42]. It has been reported that extreme events, such as the record low level of the sea ice extent in 2019, might have been caused by a large amount of ocean heat [43,44]. The average near-surface water temperature measured by a temperature sensor at a seawater intake near the bow of IBRV Araon between 13 and 16 August 2019 was $-1.27^{\circ} \mathrm{C} \pm 0.05^{\circ} \mathrm{C}$. Considering that that the bottom temperature of sea ice is near $-1.7^{\circ} \mathrm{C}$, the ocean to ice-bottom heat flux is $71.54 \mathrm{Wm}^{-2}$ [45]. Besides, the average sea surface temperature from the National Oceanic and Atmospheric Administration (NOAA) Optimum Interpolation Sea Surface Temperature version 2 (OISSTv2) product was $1 \sim 7^{\circ} \mathrm{C}$ warmer than the 1982-2019 August mean in the Beaufort Sea [46,47]. Although an in situ ice thickness measurement is not available, the thickness likely decreased over time and the large heat flux at the bottom might have affected the brine volume and dielectric constant in the ice layer, where the microwave interacts to increase the backscattering $[20,41]$. The effect of the warmer ocean on the backscattering requires additional investigation with regard to the geophysical properties of sea ice such as salinity and temperature profile in time series, along with in situ measurements of the environmental parameters and satellite images for a longer period of time.

Finally, there is feasibility for the incidence angle dependence as an indicator of which scattering is more dominant over sea ice. The incidence angle dependence is strong for the surface scattering, whereas the dependence is weak for volume scattering. We need to build up more datasets to analyze how fast the dominant scattering changes over time. In addition, the atmospheric forcing is probably the most significant driving factor, and yet, additional datasets are required. The melt pond fraction must be taken into consideration as well.

\section{Conclusions}

The substantial decline of the Arctic Sea ice extent and thickness in recent decades has replaced multi-year sea ice with thinner first-year sea ice, to a vast extent. The precise classification of multi-year and first-year sea ice can help better perceive the situation of on-going sea ice changes. High-resolution SAR data are known to distinguish such ice types; however, precise radiometric calibration is required regarding the incidence angle. This study tracked down the backscattering coefficients of a multi-year sea ice surface in motion, using a GPS tracker which was installed during a field campaign in August 2019 and 24 Sentinel-1 EW images spanning 17 days. The incidence angle dependence of the multi-year sea ice surface in $\mathrm{HH}$ - and HV-polarization were $-0.24 \mathrm{~dB} / \mathrm{deg}$ and $-0.10 \mathrm{~dB} / \mathrm{deg}$, respectively. The surface with hummocks and recently frozen melt ponds had the incidence angle dependence of which were the mixture of surface and volume scattering. The normalized backscattering coefficients in $\mathrm{HH}$ polarization gradually increased in time at a rate of $0.15 \mathrm{~dB} /$ day as the shape of ice floe became indistinguishable. The temporal variation of the HV-polarization was relatively insignificant. Air temperature had strong negative relation with the normalized backscattering coefficients in $\mathrm{HH}$-polarization, as the contribution of volume scattering increased. Other external atmospheric forces such as air pressure at mean sea level and wind gust unlikely had influences on the backscattering. Low correlation between the backscatter and wind gust suggests that the melt pond surfaces stayed frozen throughout the study period. Homogeneity of the surface had significant relation, only with the pressure at mean sea level, which was investigated using the standard deviations of the backscattering coefficients within the region of interest. Lastly, the most conspicuous finding is that this thick ice floe, which was thicker than $3 \mathrm{~m}$, most likely disintegrated in about 2 weeks, despite strong evidence of the onset of freeze-up of the ice surface. The relatively warmer ocean temperature in the region and large heat flux might have induced continuous bottom melting. Any influence of the warm water on the dielectric constant in the layer where the microwave interacted will require additional investigation 
with regard to the geophysical properties of multi-year sea ice and longer observation periods. The analysis of the backscattering coefficients of active microwave data in time series on mobile multi-year sea ice in the western Beaufort Sea during the transition period between end of melting and onset of freeze-up was carried out for the first time in this study. Results of this study are expected to complement other previous studies, which focused on winter or summer seasons in other regions of the Arctic.

Author Contributions: Conceptualization, S.H.K. and H.-C.K.; Data curation, S.H.K. and C.-U.H.; Formal analysis, S.H.K., J.-H.K., Y.-J.K., J.-W.P., H.H. and D.-J.K.; Funding acquisition, H.-C.K.; Investigation, S.H.K.; Methodology, S.H.K., H.-C.K., C.-U.H., S.L., J.-S.H., J.-H.K. and S.-Y.J.; Project administration, H.-C.K.; Resources, S.H.K., C.-U.H., S.L., J.-S.H., J.-H.K. and D.-J.K.; Supervision, H.-C.K.; Validation, S.H.K., H.-C.K., Y.-J.K. and H.H.; Visualization, S.H.K.; Writing—original draft, S.H.K.; Writing—review and editing, S.H.K. All authors have read and agreed to the published version of the manuscript.

Funding: This research was funded by Korea Research Institute, grant number PE20080.

Acknowledgments: This research was funded by the Korea Polar Research Institute (KOPRI), grand number PE20080. We thank Korea Research Institute of Ships \& Ocean Engineering (KRISO) for providing ice core data and Dr. Jeremy Wilkinson for providing buoy weather data. The thermosalinograph data (KOPRI-KPDC-00001370) was provided by KOPRI.

Conflicts of Interest: The authors declare no conflict of interest.

\section{References}

1. Curry, J.A.; Schramm, J.L.; Ebert, E.E. Sea Ice-Albedo Climate Feedback Mechanism. J. Clim. 1995, 8, 240-247. [CrossRef]

2. McBean, G.; Alekseev, G.; Chen, D.; Førland, E.; Fyfe, J.; Groisman, P.; King, R.; Melling, H.; Vose, R.; Whitfield, P. Arctic Climate-Past and Present. Arctic Climate Impact Assessment: Scientific Report; Cambridge University Press: Cambridge, UK, 2005; pp. 22-60.

3. Serreze, M.C.; Holland, M.M.; Stroeve, J. Perspectives on the Arctic's Shrinking Sea-Ice Cover. Science 2007, 315, 1533-1536. [CrossRef] [PubMed]

4. Stroeve, J.C.; Holland, M.M.; Meier, W.; Scambos, T.; Serreze, M. Arctic sea ice decline: Faster than forecast. Geophys. Res. Lett. 2007, 34. [CrossRef]

5. Kwok, R. Arctic sea ice thickness, volume, and multiyear ice coverage: Losses and coupled variability (1958-2018). Environ. Res. Lett. 2018, 13. [CrossRef]

6. Budikova, D. Role of Arctic sea ice in global atmospheric circulation: A review. Glob. Planet Chang. 2009, 68, 149-163. [CrossRef]

7. Stroeve, J.C.; Serreze, M.C.; Holland, M.M.; Kay, J.E.; Malanik, J.; Barrett, A.P. The Arctic's rapidly shrinking sea ice cover: A research synthesis. Clim. Chang. 2012, 110, 1005-1027. [CrossRef]

8. Kwok, R. Sea ice convergence along the Arctic coasts of Greenland and the Canadian Arctic Archipelago: Variability and extremes (1992-2014). Geophys. Res. Lett. 2015, 42, 7598-7605. [CrossRef]

9. Galley, R.J.; Babb, D.; Ogi, M.; Else, B.; Geilfus, N.X.; Crabeck, O.; Barber, D.G.; Rysgaard, S. Replacement of multiyear sea ice and changes in the open water season duration in the Beaufort Sea since 2004. J. Geophys. Res. 2016, 121, 1806-1823. [CrossRef]

10. Zakhvatkina, N.Y.; Alexandrov, V.Y.; Johannessen, O.M.; Sandven, S.; Frolov, I.Y. Classification of Sea Ice Types in ENVISAT Synthetic Aperture Radar Images. IEEE Trans. Geosci. Remote 2013, 51, 2587-2600. [CrossRef]

11. Han, H.; Hong, S.H.; Kim, H.C.; Chae, T.B.; Choi, H.J. A study of the feasibility of using KOMPSAT-5 SAR data to map sea ice in the Chukchi Sea in late summer. Remote Sens. Lett. 2017, 8, 468-477. [CrossRef]

12. Karvonen, J.; Simila, M.; Mäkynen, M. Open water detection from Baltic Sea ice Radarsat-1 SAR imagery. IEEE Geosci. Remote 2005, 2, 275-279. [CrossRef]

13. Karvonen, J. Evaluation of the operational SAR based Baltic Sea ice concentration products. Adv. Space Res. 2015, 56, 119-132. [CrossRef]

14. Dierking, W.; Dall, J. Sea-Ice Deformation State from Synthetic Aperture Radar Imagery_Part I: Comparison of C-and L-Band and Different Polarization. IEEE Trans. Geosci. Remote. 2007, 45, 3610-3622. [CrossRef] 
15. Casey, J.A.; Howell, S.E.; Tivy, A.; Haas, C. Separability of sea ice types from wide swath C-and L-band synthetic aperture radar imagery acquired during the melt season. Remote Sens. Environ. 2016, 174, 314-328. [CrossRef]

16. Geldsetzer, T.; Yackel, J. Sea ice type and open water discrimination using dual co-polarized C-band SAR. Can. J. Remote Sens. 2009, 35, 73-84. [CrossRef]

17. Geldsetzer, T.; Arkett, M.; Zagon, T.; Charbonneau, F.; Yackel, J.J.; Scharien, R.K. All-Season Compact-Polarimetry C-band SAR Observations of Sea Ice. Can. J. Remote Sens. 2015, 41, 485-504. [CrossRef]

18. Mäkynen, M.P.; Manninen, A.T.; Simila, M.H.; Karvonen, J.A.; Hallikainen, M.T. Incidence angle dependence of the statistical properties of C-band HH-polarization backscattering signatures of the Baltic Sea ice. IEEE T. Geosci. Remote 2002, 40, 2593-2605. [CrossRef]

19. Mäkynen, M.; Kern, S.; Rosel, A.; Pedersen, L.T. On the Estimation of Melt Pond Fraction on the Arctic Sea Ice With ENVISAT WSM Images. IEEE T. Geosci. Remote 2014, 52, 7366-7379. [CrossRef]

20. Onstott, R.G. SAR and Scatterometer Signatures of Sea Ice. In Microwave Remote Sensing of Sea Ice; Carsey, F., Ed.; American Geophysical Union: Washington, DC, USA, 1992; Volume 68, pp. 73-104. [CrossRef]

21. Mahmud, M.S.; Geldsetzer, T.; Howell, S.E.L.; Yackel, J.J.; Nandan, V.; Scharien, R.K. Incidence Angle Dependence of HH-Polarized C- and L-Band Wintertime Backscatter Over Arctic Sea Ice. IEEE T. Geosci. Remote 2018, 56, 6686-6698. [CrossRef]

22. Lubin, D.; Massom, R. Polar Remote Sensing: Volume I: Atmosphere and Oceans; Springer Science \& Business Media: Berlin, Germany, 2006; p. 320.

23. McPhee, M.G.; Maykut, G.A.; Morison, J.H. Dynamics and Thermodynamics of the Ice Upper Ocean System in the Marginal Ice-Zone of the Greenland Sea. J. Geophys. Res. Oceans 1987, 92, 7017-7031. [CrossRef]

24. Winebrenner, D.P.; Holt, B.; Nelson, E.D. Observation of autumn freeze-up in the Beaufort and Chukchi Seas using the ERS 1 synthetic aperture radar. J. Geophys. Res. Oceans 1996, 101, 16401-16419. [CrossRef]

25. Dierking, W. Mapping of Different Sea Ice Regimes Using Images From Sentinel-1 and ALOS Synthetic Aperture Radar. IEEE Trans. Geosci. Remote 2010, 48, 1045-1058. [CrossRef]

26. Thoman, R.L.; Bhatt, U.S.; Bieniek, P.A.; Brettschneider, B.R.; Brubaker, M.; Danielson, S.L.; Labe, Z.; Lader, R.; Meier, W.N.; Sheffield, G. The Record Low Bering Sea Ice Extent in 2018: Context, Impacts, and an Assessment of the Role of Anthropogenic Climate Change. Am. Meteorol. Soc. 2020, 101, S53-S58. [CrossRef]

27. Holt, B.; Digby, S.A. Processes and imagery of first-year fast sea ice during the melt season. J. Geophys. Res. Oceans 1985, 90, 5045-5062. [CrossRef]

28. Barber, D.G.; Yackel, J. The physical, radiative and microwave scattering characteristics of melt ponds on Arctic landfast sea ice. Int. J. Remote Sens. 1999, 20, 2069-2090. [CrossRef]

29. Torres, R.; Snoeij, P.; Geudtner, D.; Bibby, D.; Davidson, M.; Attema, E.; Potin, P.; Rommen, B.; Floury, N.; Brown, M. GMES Sentinel-1 mission. Remote Sens. Environ. 2012, 120, 9-24. [CrossRef]

30. Mäkynen, M.; Karvonen, J. Incidence Angle Dependence of First-Year Sea Ice Backscattering Coefficient in Sentinel-1 SAR Imagery Over the Kara Sea. IEEE T. Geosci. Remote 2017, 55, 6170-6181. [CrossRef]

31. Hersbach, H.; Bell, B.; Berrisford, P.; Horányi, A.; Sabater, J.M.; Nicolas, J.; Radu, R.; Schepers, D.; Simmons, A.; Soci, C. Global reanalysis: Goodbye ERA-Interim, hello ERA5. ECMWF Newsl. 2019, 159, 17-24.

32. Onstott, R.G.; Grenfell, T.C.; Matzler, C.; Luther, C.A.; Svendsen, E.A. Evolution of Microwave Sea Ice Signatures during Early Summer and Midsummer in the Marginal Ice-Zone. J. Geophys. Res. 1987, 92, 6825-6835. [CrossRef]

33. Ulander, L.; Carlström, A. Radar backscatter signatures of Baltic sea ice. In Proceedings of the IGARSS'91 Remote Sensing: Global Monitoring for Earth Management, Espoo, Finland, 3-6 June 1991; Volume 3, pp. 1215-1218. [CrossRef]

34. Nandan, V.; Geldsetzer, T.; Mahmud, M.; Yackel, J.; Ramjan, S. Ku-, X-and C-Band Microwave Backscatter Indices from Saline Snow Covers on Arctic First-Year Sea Ice. Remote Sens. 2017, 9. [CrossRef]

35. Jeffries, M.; Schwartz, K.; Li, S. Arctic summer sea-ice SAR signatures, melt-season characteristics, and melt-pond fractions. Polar Rec. 1997, 33, 101-112. [CrossRef]

36. Geldsetzer, T.; Mead, J.B.; Yackel, J.J.; Scharien, R.K.; Howell, S.E. Surface-based polarimetric C-band scatterometer for field measurements of sea ice. IEEE Trans. Geosci. Remote 2007, 45, 3405-3416. [CrossRef]

37. Carlström, A.; Ulander, L.M. C-band backscatter signatures of old sea ice in the central Arctic during freeze-up. IEEE Trans. Geosci. Remote 1993, 31, 819-829. [CrossRef] 
38. Zhou, X.; Chong, J.; Bi, H.; Yu, X.; Shi, Y.; Ye, X. Directional Spreading Function of the Gravity-Capillary Wave Spectrum Derived from Radar Observations. Remote Sens. 2017, 9, 361. [CrossRef]

39. Yang, J.; Comiso, J.; Walsh, D.; Krishfield, R.; Honjo, S. Storm-driven mixing and potential impact on the Arctic Ocean. J. Geophys. Res. Oceans 2004, 109. [CrossRef]

40. Graham, R.M.; Itkin, P.; Meyer, A.; Sundfjord, A.; Spreen, G.; Smedsrud, L.H.; Liston, G.E.; Cheng, B.; Cohen, L.; Divine, D. Winter storms accelerate the demise of sea ice in the Atlantic sector of the Arctic Ocean. Sci. Rep. 2019, 9, 9222. [CrossRef]

41. Yackel, J.; Geldsetzer, T.; Mahmud, M.; Nandan, V.; Howell, S.E.; Scharien, R.K.; Lam, H.M. Snow Thickness Estimation on First-Year Sea Ice from Late Winter Spaceborne Scatterometer Backscatter Variance. Remote Sens. 2019, 11, 417. [CrossRef]

42. Perovich, D.K.; Richter-Menge, J.A.; Jones, K.F.; Light, B. Sunlight, water, and ice: Extreme Arctic sea ice melt during the summer of 2007. Geophys. Res. Lett. 2008, 35. [CrossRef]

43. Woodgate, R.A.; Weingartner, T.; Lindsay, R. The 2007 Bering Strait oceanic heat flux and anomalous Arctic sea-ice retreat. Geophys. Res. Lett. 2010, 37. [CrossRef]

44. Perovich, D.K.; Richter-Menge, J.A.; Jones, K.F.; Light, B.; Elder, B.C.; Polashenski, C.; Laroche, D.; Markus, T.; Lindsay, R. Arctic sea-ice melt in 2008 and the role of solar heating. Ann. Glaciol. 2011, 52, 355-359. [CrossRef]

45. Omstedt, A.; Wettlaufer, J. Ice growth and oceanic heat flux: Models and measurements. J. Geophys. Res. 1992, 97, 9383-9390. [CrossRef]

46. Fetterer, F.; Knowles, K.; Meier, W.N.; Savoie, M.; Windnagel, A.K. Sea Ice Index, Version 3: Regional Daily Data; NSIDC: Boulder, CO, USA, 2017. [CrossRef]

47. Timmermans, M.L.; Ladd, C. Arctic Report Card: Update for 2019. Available online: https://arctic.noaa.gov/ Report-Card/Report-Card-2019/ArtMID/7916/ArticleID/840/Sea-Surface-Temperature (accessed on 2 January 2020).

(C) 2020 by the authors. Licensee MDPI, Basel, Switzerland. This article is an open access article distributed under the terms and conditions of the Creative Commons Attribution (CC BY) license (http://creativecommons.org/licenses/by/4.0/). 